\title{
Rancang Bangun Sistem Informasi Pemesanan Kue Kota Pontianak Menggunakan Metode Waterfall
}

\author{
Deasy Purwaningtias, Deni Risdiansyah*, Muhammad Sony Maulana, Agung Sasongko \\ Fakultas Teknik dan Informatika, Program Studi Sistem Informasi, Universitas Bina Sarana Informatika, Potianak, Indonesia \\ Email: ${ }^{1}$ deasy.dwg@bsi.ac.id, ${ }^{2}$ deni.drx@bsi.ac.id, ${ }^{3}$ muhammad.sony.mom@bsi.ac.id, ${ }^{4}$ agung.ako@bsi.ac.id \\ Submitted: 15/12/2021; Accepted: 29/12/2021; Published: 31/12/2021
}

\begin{abstract}
Abstrak-Pertumbuhan bisnis di Indonesia terus mengalami peningkatan, ini terbukti dengan banyaknya bidang usaha baru yang terus muncul. Dari bidang usaha tersebut salah satunya adalah usaha bakery. Pelaku usaha ini hanya dilakukan oleh produsen besar, UMKM tradisional ternyata menjadi penyumbang terbesar untuk jenis usaha serupa. Terbukti dari $100 \%$ pegiat usaha ini ternyata sekitar $60 \%$ pelaku usahanya dilakukan oleh UMKM tradisional. Tidak sedikit pelaku usaha dibidang bakery menjalankan usahanya secara konvensional yang berdampak dengan pendapatan mereka. Padahal keberadaan sistem informasi didalam dunia bisnis dan manajemen adalah untuk melayani aneka ragam kebutuhan dan bisa menjadi kunci untuk manajemen yang lebih baik dan bisa menjadi keberhasilan dalam menjalankan bisnis itu sendiri. Untuk itu penelitian ini bertujuan membuat sebuah sistem informasi pemesanan kue berbasis website. Adapun metode pengembangan perangkat lunak yang di gunakan dalam penelitian ini adalah metode air terjun (waterfall). Sistem informasi ini dibangun menggunakan Framework Codeigniter. Dengan adanya sistem ini maka diharapkan dapat membantu para pelanggan dalam hal mencari informasi pemesanan kue dengan mudah di kota pontianak secara cepat dan akurat.
\end{abstract}

Kata Kunci: Sistem Informasi; Pemesanan Kue; Website; Waterfall; Codeigniter

\begin{abstract}
Business growth in Indonesia continues to increase, as evidenced by the many new business fields that continue to emerge. One of these business fields is the bakery business. These business actors are only carried out by large producers, traditional micro small and medium enterprises have turned out to be the biggest contributors to this type of business. It is evident from $100 \%$ of these business activists that around $60 \%$ of their businesses are carried out by traditional micro small and medium enterprises. Not a few business actors in the bakery sector run their business conventionally which has an impact on their income. Whereas the existence of information systems in the world of business and management is to serve various needs and can be the key to better management and can be a success in running the business itself. For this reason, this study aims to create a websitebased cake ordering information system. The software development method used in this research is the waterfall method. This information system is built using the CodeIgniter Framework. With this system, it is hoped that it can help customers in finding information on ordering cakes easily in Pontianak City quickly and accurately.
\end{abstract}

Keywords: Information System; Cake Ordering; Website; Waterfall; Codeigniter

\section{PENDAHULUAN}

Perkembangan bisnis kue di Indonesia terus mengalami pertumbuhan. Baik usaha kecil, menengah maupun besar. Baik dalam bentuk industri maupun boutique bakery [1]. Peningkatan permintaan pada kue ini diikuti juga dengan semakin berkembangnya jenis dari kue itu sendiri. Peningkatan ini berpengaruh karena munculnya aneka jenis kue yang baru. Pelaku usahanya 60\% Usaha Mikro Kecil dan Menengah (UMKM) tradisional, sedangkan 20\% produsen besar, sisanya $12 \%$ ialah produsen roti artisan [2]. Tentunya setiap perusahaan melakukan berbagai upaya untuk membuat perusahaan tersebut tetap eksis, berkembang, dan yang pasti agar dapat bersaing dengan perusahanperusahan lain. Sistem proses bisnis penjualan yang dilakukan mayoritas UMKM-UMKM yang ada masih belum memanfaatkan perkembangan Teknologi Informasi sehingga terhambatnya perkembangan perusahaan [3]. Di kota Pontianak sendiri dalam proses pemesanan kue kita disarankan untuk melakukan secara langsung ditoko fisik, karena pelaku usaha kue tersebut masih menggunakan sistem konvensional yaitu dimana pelanggan harus datang langsung ke toko untuk memilih jenis kue yang diinginkan serta membayar secara tunai.

Padahal dengan pesatnya kemajuan teknologi internet, membuat sistem perniagaan yang awalnya berjalan secara konvensional (toko, kios, mall) bermigrasi atau setidaknya dibuat pula dalam bentuk sistem perniagaan elektronik (Electronic Commerce/E-Commerce). Electronic Commerce merupakan sebuah idiom yang menjadi domain istilah bagi seluruh sistem perniagaan dengan media elektronik, utamanya menggunakan media internet [4]. Keberadaan sistem informasi didalam dunia bisnis dan manajemen adalah untuk melayani aneka ragam kebutuhan sehingga perlu diberikan lebih banyak perhatian pada teknologi sistem informasi karena teknologi tersebut merupakan kunci untuk manajemen yang lebih baik dan bisa menjadi keberhasilan dalam menjalankan bisnis itu sendiri [5]. Toko yang telah menggunakan sistem penjualan secara online berbasis website ataupun mobile, dapat membantu sebuah perusahaan atau pengusaha agar dapat melakukan pemasaran yang lebih luas dan juga dapat memudahkan pelanggan dalam melakukan pembelian tanpa datang langsung ke toko.

Dengan adanya penelitian ini diharapkan dapat membantu para pelaku usaha Bakery terutama pelaku UKM yang ada di Kota Pontianak dalam memasarkan produk yang mereka miliki. Sistem informasi ini berbasis website, artinya sistem informasi pemesanan kue ini dapat diakses menggunakan berbagai jenis device seperti Personal Computer (PC), laptop maupun smartphone. 


\section{METODOLOGI PENELITIAN}

\subsection{Metode Waterfall}

Metode waterfall adalah sebuah metode yang sering juga disebut model sekuensial linier (sequential linear) atau alur hidup klasik (classic life cycle) [6]. Metode air terjun ini menyediakan pendekatan alur hidup perangkat lunak secara sekuensial atau terurut dimulai dari analisis, desain, pengodean, pengujian, dan tahap pendukung (support) [7]. Metode ini memiliki 5 tahapan antara lain sebagai berikut [8]:

1. Analisa Kebutuhan Sistem

Pada tahap ini pembuatan sistem diperlukan suatu komunikasi yang bertujuan untuk memahami software yang diharapkan perngguna dan batasan software. Informasi ini biasanya didapat melalui wawancara, survey atau diskusi, informasi tersebut dianalisis untuk mendapatkan data yang dibutuhkan oleh pengguna.

2. Desain

Proses desain menerjemahkan kebutuhan pengguna dalam sebuah dokumen aplikasi yang dapat diperkirakan kualitasnya sebelum proses coding dimulai, proses ini berfungsi sebagai dasar perancangan untuk mengubah data-data dari analis menjadi sebuah rancangan yang terdiri dari rancangan database, software architecture danuser interface.

3. Code Generation

Tahapan ini merupakan lanjutan dari tahapan desain, yaitu mentranslasi desain menjadi sebuah program.Tahap ini menghasilkan suatu program yang sesuai dengan desainnya.

4. Testing

Program yang telah dibuat harus diuji terlebih dahulu untuk memastikan bahwa program layak dari segi logis maupun fungsional. Pengujian ini disamping untuk meminimalisir kesalahan dapat juga untuk menambah kekurangan yang ada.

5. Support

Ini merupakan tahap terakhir dalam model waterfall. Software yang telah jadi dijalankan tetap dilakukan pemeliharaan, pemeliharaan yang dilakukan termasuk dalam memperbaiki kesalahan yang tidak ditemukan pada langkah sebelumnya, perbaikan implementasi unit system dan peningkatan jasa system sebagai kebutuhan baru.

Dari pemaparan di atas dapat digambarkan metode Waterfall sebagai berikut:

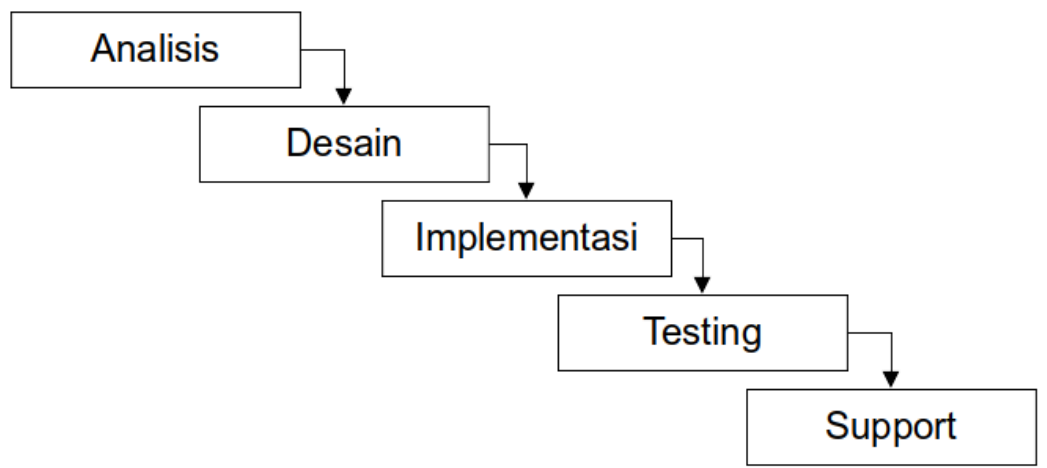

Gambar 1. Tahapan Penelitian Metode Waterfall

\subsection{Sistem Informasi}

Sistem informasi merupakan gabungan dari empat bagian utama. Keempat bagian utama tersebut mencakup perangkat lunak (software), perangkat keras (hardware), infrastruktur, dan Sumber Daya Manusia (SDM) yang terlatih. Keempat bagian utama ini saling berkaitan untuk menciptakan sebuah sistem yang dapat mengelola data menjadi informasi yang bermanfaat [9]. Sistem Informasi merupakan kumpulan elemen yang saling berhubungan satu sama lain untuk menunjang pengambilan keputusan dan pengawasan [10].

\subsection{Website}

Website merupakan kumpulan dari halaman-halaman web yang mengandung informasi berupa teks, gambar, dan animasi yang bersifat dinamis [6]. Website adalah keseluruhan halaman- halaman web yang terdapat dalam sebuah domain yang mengandung informasi [11].

\subsection{Framework Codeigniter}

CodeIgniter adalah sebuah framework php yang bersifat open source dan menggunakan metode MVC (Model, View, Controller) untuk memudahkan developer atau programmer dalam membangun sebuah aplikasi berbasis web tanpa harus membuatnya dari awal [12]. Codeigniter merupakan framework yang dirancang agar memudahkan developer dalam membuat sebuah website [10]. 


\subsection{Penjualan}

Penjualan adalah bagian dari kegiatan pemasaran yang memiliki makna yang luas yang meliputi berbagai fungsi perusahaan, pemasaran adalah sistem keseluruhan dari kegiatan usaha yang ditujukan untuk merencanakan, menentukan harga, memromosikan untuk dapat dipasarkan[13].

\subsection{Pembelian}

Pembelian adalah sebuah perusahaan dagang pembelian meliputi pembelian aktiva produktif, pembelian barang dagangan serta pembelian barang dan jasa lain dalam rangka kegiatan usaha[13].

\subsection{Kue}

Kue adalah kudapan atau makanan ringan yang bukan makanan utama. Kue umumnya bercita rasa manis, gurih atau asin. Kue sering kali diartikan sebagai makanan ringan yang dibuat dari adonan tepung, baik tepung beras, tepung sagu, tapioka, atau tepung terigu lainnya. Kue memiliki banyak variasi bentuk dan rasa sehingga cocok untuk berbagai kalangan[14].

\section{HASIL DAN PEMBAHASAN}

Pada penelitian ini proses pengembangan perangkat lunak menggunakan metode Waterfall. Metode Waterfall dapat digunakan baik pada sistem kecil maupun sistem yang besar, hal ini bertujuan untuk memudahkan langkah pengembangan awal bagi calon pengguna untuk lebih mengetahui sistem seperti apa yang diinginkan. Berikut ini adalah tahapan yang dilakukan pada pengembangan sistem informasi pemesanan kue dengan menggunakan metode waterfall yang terdiri dari :

1. Analisa Kebutuhan Sistem

Pada tahap ini peneliti melakukan survei dan wawancara kepada beberapa toko kue yang ada di Kota Pontianak seperti Cotton Bread, D’Bread Recipe, Whitley Bakery, Roti Durian Orchard dan Roti Gemes guna menemukan rumusan sistem informasi yang dibutuhkan.

2. Desain

Setelah melakukan analisa maka peneliti melakukan desain antarmuka agar sistem informasi yang dibangun bisa sesuai kebutuhan dan tepat sasaran.

3. Code Generation

Desain yang telah disepakati akan dieksekusi kedalam naskah program untuk dibuat sistem informasi pemesanan kue sesuai dengan hasil analisa.

4. Testing

Setelah sistem informasi pemesanan kue selesai dibuat maka tahap selanjutnya melakukan uji coba. Uji coba dilakukan dengan metode Blackbox Testing dan didapat hasil memuaskan serta dianggap layak untuk diterapkan.

5. Support

Ini merupakan tahap terakhir yaitu melakukan pemeliharaan dan perbaikan dari bug atau kesalahan yang ada pada sistem informasi pemesanan kue yang sudah berjalan.

Tahapan Analisis merupakan tahapan paling awal dari pengembangan aplikasi yang menjadi pondasi menentukan keberhasilan mengenai suatu informasi yang dihasilkan nantinya [15].

\subsection{Analisa Kebutuhan Pengguna}

Tahapan ini penulis mengumpulkan data berupa kebutuhan fungsional dari sisi Administrator dan Konsumen.

1. Admin

a. Admin bisa melakukan login dengan memasukan email dan password.

b. Admin dapat menambah kategori menu, melihat kategori menu, mengupdate kategori menu, menghapus kategori menu, melihat data pemesanan pelanggan, melihat data pelanggan, melihat konfirmasi pembayaran pelanggan, melihat laporan penjualan, logout.

c. Admin dapat melakukan pencatatan keuangannya setiap bulan, melalui dari data pembelian yang terdapat pada website.

2. Konsumen

a. Pelanggan dapat melakukan login atau membuat akun.

b. Pelanggan dapat melihat halaman produk kue yang tersedia, harga kue, stok kue yang tersedia, deskripsi kue, melihat keranjang belanja, melihat informasi kue yang telah di order, checkout menu yang telah di order, memilih tipe pembayaran, melakukan konfirmasi pembayaran dan logout.

c. Pelanggan dapat melihat informasi pemesanan kue pada website toko kue di Kota Pontianak.

d. Pelanggan dapat melakukan pemesanan kue dalam jumlah banyak, untuk acara meeting ataupun arisan. 


\subsection{Use Case Diagram}

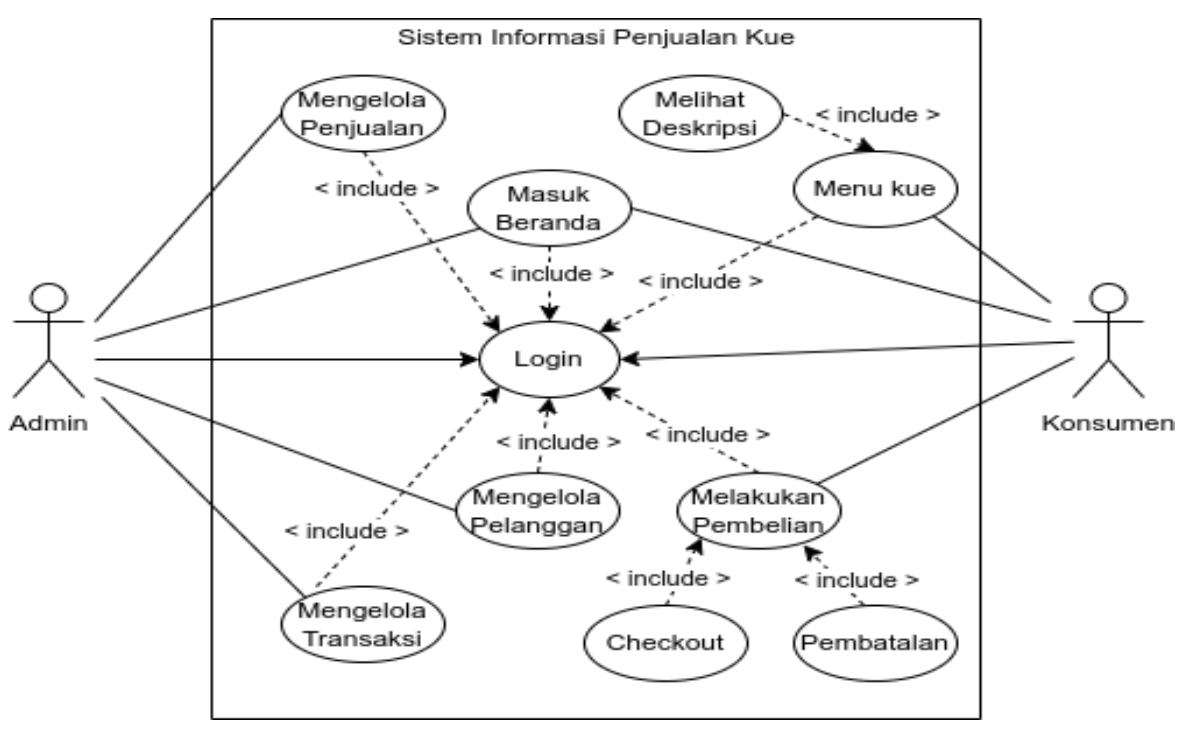

Gambar 2. Use Case Diagram Sistem Informasi Penjualan Kue

Pada diagram diatas terdapat 10 use case dengan 2 aktor didalamnya. Setiap usecase selain login hanya dapat diakses oleh Administrator dan Konsumen sebagai aktor apabila aktor telah melakukan login terlebih dahulu. Menu yang terdapat pada halaman beranda akan menyesuai dengan level akses yang melakukan login.

\subsection{Implementasi Program}

Berisi hasil implementasi penerapan metode, ataupun hasil dari pengujian metode.

1. Login

Pada halaman ini Pelanggan harus masukan email dan password agar dapat masuk ke halaman pelanggan.

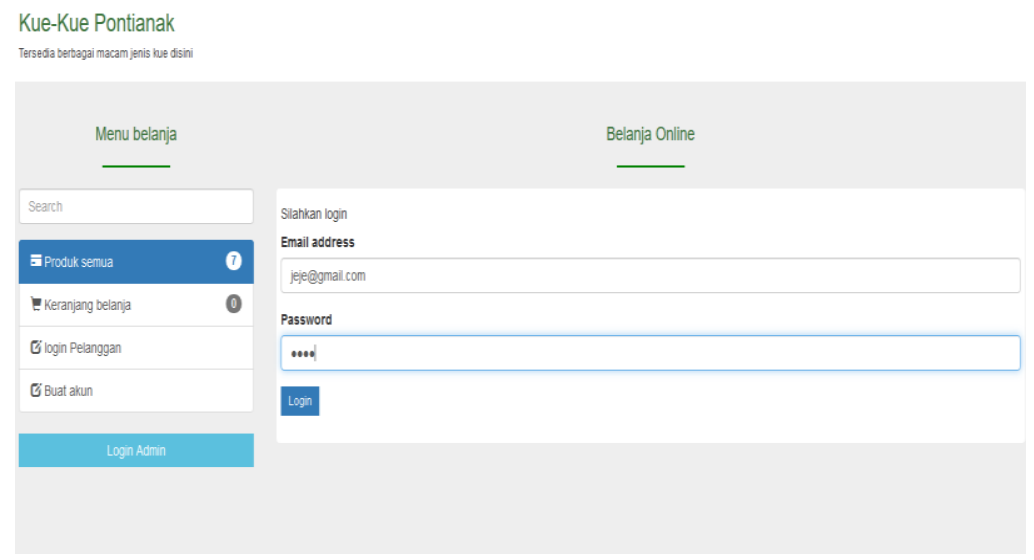

Gambar 3. Desain Login

2. Beranda

Pada halaman ini menampilkan halaman antar muka untuk pelanggan.

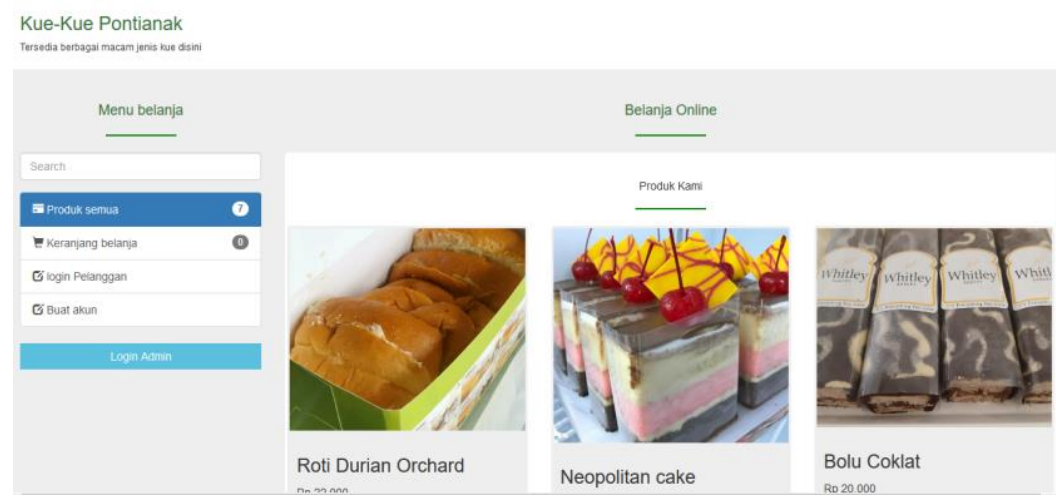

Gambar 4. Desain Beranda 
Building of Informatics, Technology and Science (BITS)

Volume 3, No 3, Desember 2021 Page: 405-411

ISSN 2684-8910 (media cetak)

ISSN 2685-3310 (media online)

DOI 10.47065/bits.v3i3.1037

3. Keranjang Belanja

Pada halaman ini pelanggan dapat melakukan order kue sesuai dengan keinginan dari dan dimasukkan kedalam keranjang belanja.

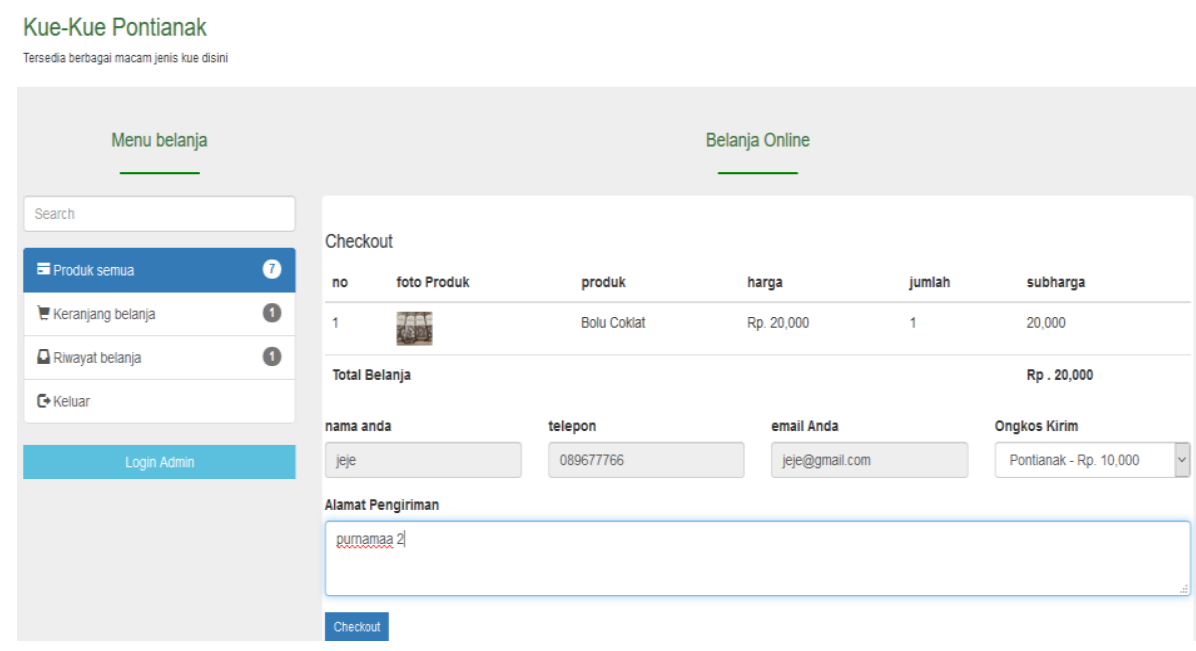

Gambar 5. Desain Laman Keranjang Belanja

4. Checkout Keranjang Belanja

Pada halaman ini pelanggan dapat melakukan checkout pesanan dari halaman keranjang belanja.

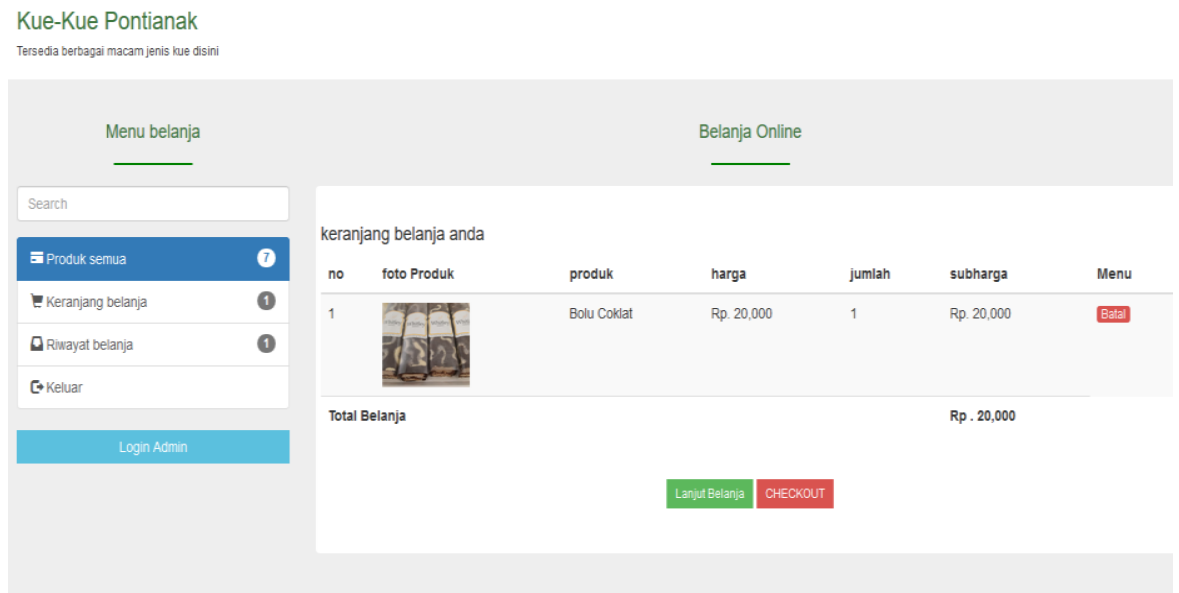

Gambar 6. Desain Checkout Keranjang Belanja

5. Nota Pembelian

Pada halaman ini pelanggan dapat melihat dan screenshoot nota pembelian.

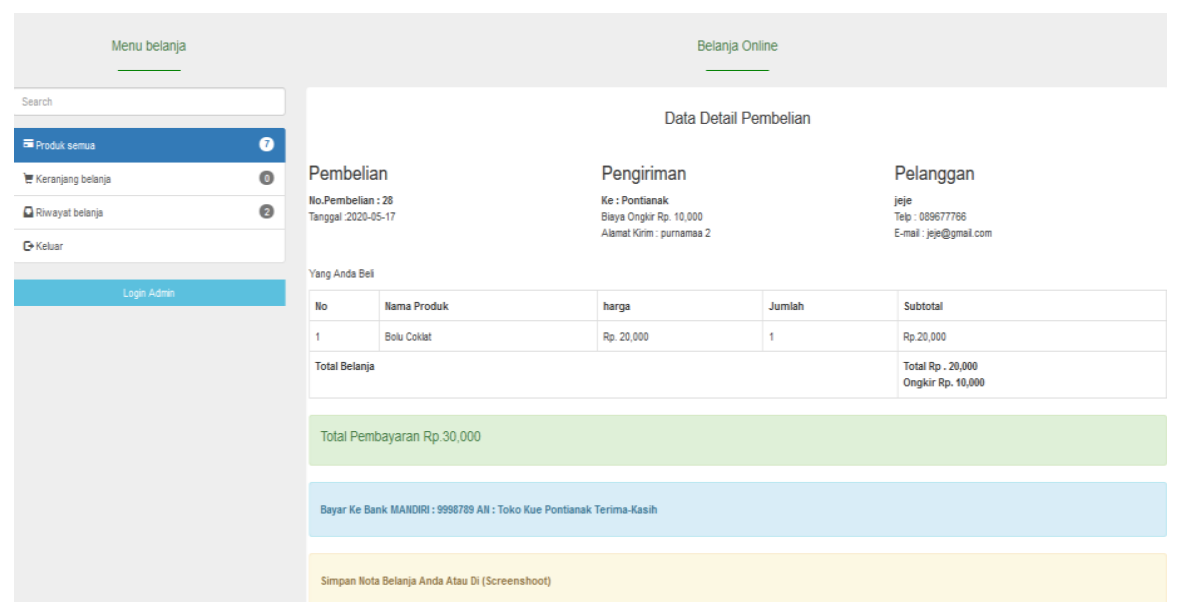

Gambar 7. Desain Nota Pembelian 
Building of Informatics, Technology and Science (BITS)

Volume 3, No 3, Desember 2021 Page: 405-411

ISSN 2684-8910 (media cetak)

ISSN 2685-3310 (media online)

DOI 10.47065/bits.v3i3.1037

6. Riwayat Belanja

Pada halaman ini pelangan dapat melihat riwayat belanja.

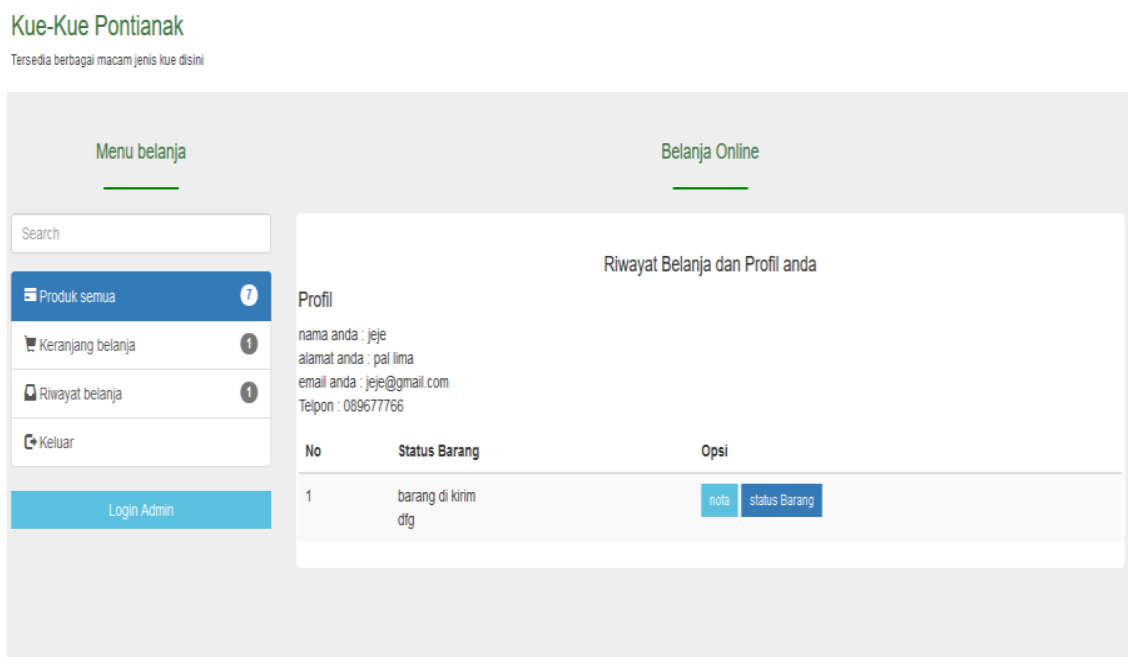

Gambar 8. Desain tampilan Riwayat Belanja

\section{KESIMPULAN}

Penelitian ini menghasilkan sistem informasi pemesanan kue berbasis website untuk pemesanan kue wilayah Kota Pontianak. Hasil pengumpulan kebutuhan yang telah dilakukan didapat 7 kebutuhan fungsional. Calon konsumen harus mendaftarkan diri agar dapat melakukan pemesanan/pembelian kue secara online. Website ini berisikan informasi yang dibutuhkan oleh calon konsumen mengenai jenis-jenis kue yang tersedia.

\section{UCAPAN TERIMA KASIH}

Terima kasih kepada Cotton Bread, D’Bread Recipe, Whitley Bakery, Roti Durian Orchard dan Roti Gemes di Kota Pontianak yang telah mendukung dan memberikan informasi yang sangat berarti dalam pembuatan Sistem Informasi Pemesanan Kue berbasis website di Kota Pontianak ini.

\section{REFERENCES}

[1] N. N. Azizah, "Roti rumahan, jajanan sepanjang masa yang makin laris di marketplace," www.alinea.id, 2021. https://www.alinea.id/bisnis/roti-rumahan-jajanan-yang-makin-laris-di-marketplace-b2c4G94IV.

[2] A. Hidayat, "Bisnis roti dan kue Indonesia bertumbuh 10\%," kontan.co.id, 2017. https://industri.kontan.co.id/news/bisnisroti-dan-kue-indonesia-bertumbuh-10.

[3] A. ABDURRAHMAN, "Metode Waterfall Untuk Sistem Penjualan," 1/12/2017, vol. 2, no. 1, pp. 95 - 104, 2017, [Online]. Available: https://repository.bsi.ac.id/index.php/unduh/item/236584/Metode-Waterfall-Untuk-Sistm-Penjualan.pdf.

[4] E. S. Gardner, "Analisis struktur kovarians indikator terkait kesehatan pada lansia di rumah dengan fokus pada kesehatan subjektif," vol. 7, no. 1, p. 1939, 2016.

[5] A. Permatasari, "Rancangan Sistem Informasi Penjualan pada Toko Kue," ComTech Comput. Math. Eng. Appl., vol. 6, no. 1, p. 31, 2015, doi: 10.21512/comtech.v6i1.2284.

[6] W. S. Dharmawan, D. Purwaningtias, and D. Risdiansyah, "Penerapan Metode SDLC Waterfall Dalam Perancangan Sistem Informasi Administrasi Keuangan Berbasis Desktop,” J. Khatulistiwa Inform., vol. 6, no. 2, pp. 159-167, 2018, doi: 10.31294/khatulistiwa.v6i2.160.

[7] F. Fandhilah, A. O. Rindina, D. Ferdiansyah, and A. Ishaq, "Implementasi Metode Waterfall Pada Pengembangan Sistem Informasi Penerimaan Siswa Baru Berbasis Web Pada SMK Negeri 2 Adiwerna," Indones. J. Softw. Eng., vol. 5, no. 1, pp. 104-113, 2019, doi: 10.31294/ijse.v5i1.5869.

[8] H. D. Kussetiawan, A. Al Kaafi, R. I. Nurachim, and S. D. Saraswati, "Rancang Bangun Sistem Informasi Akuntansi Penjualan dan Pembelian Pada Koperasi Karyawan Senayan City Jakarta Menggunakan Metode Waterfall," Build. Informatics, Technol. Sci., vol. 2, no. 2, pp. 135-140, 2020, doi: 10.47065/bits.v2i2.535.

[9] D. Risdiansyah, "Perancangan Sistem Informasi Bimbingan Konseling Berbasis Desktop pada SMA Kemala Bhayangkari 1 Kubu Raya Deni," Khatulistiwa Inform., vol. 5, no. 2, pp. 86-91, 2017, [Online]. Available: https://ejournal.bsi.ac.id/ejurnal/index.php/khatulistiwa/article/view/2884.

[10] D. Purwaningtias, R. Sabaruddin, I. Wulandari, and D. Risdiansyah, "Sistem Informasi Manajemen Akademi Seni Bela Diri Karate Indonesia (Simaski) Kalimantan Barat,” Jik), vol. 5, no. 2, 2021, [Online]. Available: https://repository.bsi.ac.id/index.php/repo/viewitem/29559.

[11] D. Saputra, Martias, and R. T. Sarfani, "Aplikasi Sistem Manajemen Logistik Obat pada Dinas Kesehatan Kota Pontianak Berbasis Web," Khatulistiwa Inform., vol. VI, no. 1, pp. 29-45, 2018. 
[12] M. Destiningrum and Q. J. Adrian, "Sistem Informasi Penjadwalan Dokter Berbassis Web Dengan Menggunakan Framework Codeigniter (Studi Kasus: Rumah Sakit Yukum Medical Centre)," J. Teknoinfo, vol. 11, no. 2, p. 30, 2017, doi: 10.33365/jti.v11i2.24

[13] A. N. Nurhayati, A. Josi, and N. A. Hutagalung, "Rancang Bangun Aplikasi Penjualan Dan Pembelian Barang Pada Koperasi Kartika Samara Grawira Prabumulih,” J. Teknol. dan Inf., vol. 7, no. 2, pp. 13-23, 2018, doi: 10.34010/jati.v7i2.490.

[14] A. A. Alvin, Y. Kasih, and S. M. Elizabeth, "ALVIN' S CAKE ( Perencanaan Pendirian Usaha Kue Basah Tradisional Khas Palembang )," pp. 2-15.

[15] A. Sasongko, A. Mustopa, and D. Risdiansyah, "Perancangan Prototipe Aplikasi Mobile Ikatan Alumni (StudiKasus Universitas Bina Sarana Informatika)," vol. 9, no. 3, pp. 307-314, 2021, doi: 10.26418/justin.v9i3.47096. 